\title{
The construct validity of session RPE during an intensive camp in young male Karate athletes
}

\author{
Johnny Padulo',2 \\ Helmi Chaabène ${ }^{2,3}$ \\ Montassar Tabben ${ }^{4}$ \\ Monoem Haddad 5 \\ Cecilia Gevat ${ }^{6}$ \\ Stefano Vando ${ }^{7}$ \\ Lucio Maurino $^{8}$ \\ Anis Chaouachi² \\ Karim Chamari'2,9
}

1 Sport Science, University e-Campus, Novedrate, Italy

2 Tunisian Research Laboratory "Sports Performance Optimization" National Center of Medicine and Science in Sport, Tunis, Tunisia

3 ISSEP Ksar-Saïd, Manouba University, Tunisia

4 CETAPS, Rouen University, Rouen, France

5 Sport Science Program, College of Arts and Sciences, Qatar University, Doha, Qatar

6 Ovidius University of Constanta, Romania

7 Faculty of Medicine and Surgery, University of "Tor Vergata" Rome, Italy

8 Italian Federation Martial Art, Rome, Italy

9 Athlete Health and Performance Research Centre, ASPETAR, Qatar; Orthopaedic and Sports Medicine Hospital, Doha, Qatar

Corresponding author:

Johnny Padulo

Sport Science, University e-Campus

Via Isimbardi, 10

22060 Novedrate, Italy

E-mail: sportcinetic@gmail.com

\section{Summary}

Background: the aim of this study was to assess the validity of the session rating of perceived exertion (RPE) method and two objective HR-based methods for quantifying karate's training load (TL) in young Karatekas. Methods: eleven athletes (age 12.50 \pm 1.84 years) participated in this study. The training period/camp was performed on 5 consecutive days with two training session (s) per-day (d). Construct validity of RPE method in young Karate athletes, was studied by correlation analysis between RPE session's training load and both Edwards and Banister's training impulse score' method. Results: significant relationship was found between inter-day $(n-11 \times d-5 \times s-2=110)$ sessions RPE and Edwards ( $r$ values from 0.84 to $0.92 \mathrm{p}<0.001$ ) and Banister's ( $r$ values from 0.84 to $0.97 \mathrm{p}<0.001$ ), respectively. Conclusion: this study showed that session-RPE can be considered a valid method for quantifying karate's training load in young karate athletes.

KEY WORDS: young athletes, karate training, perceived exertion, combat sports, heart rate.

\section{Introduction}

Karate is well known as one of the most popular martial arts in the world ${ }^{1}$. The studies on karate's performance analysis have shown that this sport' combats requires repetitions of intensive short sequences of attack and/or defence that are interrupted by brief periods of active and/or passive recovery ${ }^{2-4}$. Another study on the physiological profile of elite karate competitors reported that both the aerobic and anaerobic metabolisms need to be developed in these athletes ${ }^{5}$. In the context of developing the latter physiological pathways ${ }^{6}$, several studies have stressed the importance of performing appropriate training loads (TL) to enhance performance and have demonstrated, for instance, that some changes in performance can be mainly attributed to varying periods of easy and hard training loads ${ }^{7,8}$. Nevertheless, for being able to schedule and monitor training loads in karate athletes, there is a need for a valid and accurate tool for assessing TLs in this sport ${ }^{9}$. In that regard, the coach's intuition about training loads may not be reliable for accurately monitoring training, given the complexity of training mode interactions ${ }^{10}$. Unsuitable and uncontrolled training might stimulate detraining, nonfunctional overreaching, overtraining or injury and, then, performance decrement (from some days to months). Negative outcome of these symptoms could make end of athletic career. Several methods that integrate exercise intensity and volume into a single score have, thus, been suggested 8,11 . Most of these methods, which rely on heart rate $(\mathrm{HR})$ response to exercise intensity and duration, provide objective measures of physical effort ${ }^{12-15}$ that might allow for the quantification of a training session as a unit "dose" of physical effort ${ }^{16}$. Although HR-based methods provide objective measures of TL, they appear to be a poor method for evaluating intensity during high-intensity exercise (i.e., intermittent and/or plyometric exercises) ${ }^{11}$. A method based on the per- 
ceived exertion during the entire training session (i.e., session-RPE) was suggested by Foster et al. ${ }^{11}$. This approach has been received increasing attention in recent years in martial arts ${ }^{9}$. Foster et al. ${ }^{11}$ simplified the quantification of TL by substituting HR data by a session-RPE measure.

RPE is based on the observation that athletes inherently monitor the physiological stress they experience during exercise. Session-RPE has been shown to be a simple and valid method for quantifying whole training session intensity for both steady-state and intermittent exercise ${ }^{17}$. Moreover, RPE has been correlated with many physiological measures of exercise intensity, such as oxygen consumption $\left(\mathrm{VO}_{2}\right)$, ventilation, respiratory rate, blood lactate concentration, HR and electromyography activity, during a variety of exercise protocols ${ }^{18-20}$. Impellizzeri et al. ${ }^{21}$ studied the relationship between the session-RPE method and three objective methods (Banister's TRIMP, Edwards' summated-heart-rate-zones method, and Lucia's TRIMP) in soccer players during training and match play. Authors reported a significant individual correlations between the session-RPE method and Banister's TRIMP method ${ }^{22}$ (ranged from $r=0.50$ to 0.77 ), and between the session-RPE method and Edwards' summated-heart-rate-zones method ${ }^{23}$ (ranged from $r=0.54$ to 0.78 ). A recent study by Milanez et al. ${ }^{24}$ analyzed the relationships between the RPE of a whole exercise session and objective measures of exercise intensity during a single karate training session. Significant relationships $(p<0.05)$ were found between the mean TL session-RPE and mean lactate, percentage of maximum $\mathrm{HR}$, and percentage of HR reserve. However, the relationship between session-RPE-derived TLs and HR-based TLs has not been fully assessed in elite karate players across a range of exercise modes.

Through in senior karate athletes RPE was investigated $^{25}$ seems that the RPE is related on age as demonstrated by Barroso et al. ${ }^{10}$ in swimmers. Therefore, this study assessed the validity of the sessionRPE method across all typical training modes of a karate training program in young karate practitioners $^{13}$. The studied sessions included technical workouts and specific physical training sessions. To do so, the session-RPE method was compared with two HR-based methods (Edwards ${ }^{23}$ and Banister et al. ${ }^{22}$ ) aiming at quantifying internal TL.

\section{Material and methods}

\section{Subjects}

Eleven male youth karate athletes, aged between 10 and 15 yrs (means $\pm S D$ : age: $12.50 \pm 1.84$ years, height: $159 \pm 8.66 \mathrm{~cm}$, body mass: $50.30 \pm 9.42 \mathrm{~kg}$, BMI: $19.9 \pm 3.98 \mathrm{~kg} \cdot \mathrm{m}^{-2}, \mathrm{HR}_{\max } 207 \pm 1.84 \mathrm{bpm}$ ) volunteered to participate in the present study. All participants (i.e. both experimental and control group) had at least 4 years of karate training background with two to three karate training session per -week (total
3-4 hours per week). The participants were healthy without any muscular, neurological or tendineous issues/injuries. None of the subjects ever underwent any endurance strenuous activity or resistance training outside of their normal training program. The study conformed to the Declaration of Helsinki 1964 and was conducted after approval from the local University Ethics Committee wich followed the ethical standard of the Muscles, Ligaments and Tendons Journal $^{26}$. The procedures, risks and goals were explained to the participants and their parents and written parental consent was obtained prior to participation in addition to the subjects' consent. The latter, knew that they could withdraw from the study at any time without penalty.

\section{Experimental set-up}

According to the Italian Federation of Martial Arts (FILKAM) guidelines, participants took part in a 1-wk Karate training camp consisting of one to two daily sessions planned by the team' coach. Maximum heart rate $\left(H R_{\max }\right)$ was estimated $(220-\text { age })^{27}$. Athletes were involved in two 60 minute training session's per-day (morning session and afternoon session for seven consecutive days) during the Summer Camp ${ }^{13}$ included specific karate exercises performed as follows:

- 10 minutes of coordinative trunk, arms (simultaneity rotation: right $v s$ left) and legs exercises (alternating rotation: right $v s$ left) in different body planes in forward-backward displacement (distance of 15 meters).

- 15 minutes of flexions, lunges and extra-rotations of lower limbs exercises in different body planes followed by dynamic stretching (DS) postures ${ }^{28}$ performed in standing and seated positions. DS consisted of one sets of 7-min, five exercises with $30 \mathrm{sec}$ each (i.e. five muscle groups: quadriceps, hamstrings, plantar flexors, adductors and hip flexors).

- Finally, $35 \mathrm{~min}$ of specific karate skills including upper and lower limb offensive and defensive techniques.

In total, 10 training sessions were performed during the training camp including one formal Karate (Kata) competition.

\section{Monitoring training loads}

Daily individual training load was calculated using the Foster's session-RPE procedure ${ }^{11}$. This method involved multiplying the training duration in minutes by the mean training intensity. The session-RPE scale (Tab. 1) is based on the Borg category ratio RPE scale and then modified by Foster et al. ${ }^{11}$ (CR-10), which translates the athlete's perception of effort into a numerical score between 0 and 10. This test is designed to ask the athlete to respond to a simple question. "How was your workout?" with the goal of getting an 
Table 1. CR10-scale modified by Foster et al. ${ }^{11}$

\begin{tabular}{ll}
\hline Rating & Descriptor \\
\hline 0 & Rest \\
1 & Very easy \\
2 & Easy \\
3 & Moderate \\
4 & Somewhat hard \\
5 & Hard \\
6 & \\
7 & Very hard \\
8 & \\
9 & \\
10 & Maximal \\
\hline
\end{tabular}

uncomplicated response that reflects the athlete's global impression of the workout. In the present study, the validated French version of the CR10-scale was used ${ }^{9}$. All athletes had been familiarized to this scale before the start of the study ( 3 wk preceding the training camp) and followed standardized instructions for RPE.

Each athlete's RPE was collected approximately 30min after each Karate session to ensure that the perceived exertion referred to the whole session rather than the most recent (end-of-session) exercise intensity. During the Karate competition, athletes' RPEs were collected $\sim 5$-min after each Karate fight to ensure that the perceived effort referred to the Karate combat. Fight session-RPE was calculated by multiplying this fight RPE by Karate fight duration.

\section{Criterion methods for quantifying physical train- ing loads}

Two HR-based training load methods were used to measure internal Training Loads (TL): Banister TRIMP and Edwards TL 22,23. The Banister TRIMP22 tries to weight the session duration using an exponential factor, as in the following formula:

- $\mathrm{TD} \times \mathrm{HR}_{\mathrm{R}} \times 0.64 \mathrm{e}^{1.92 . \mathrm{HR}_{\mathrm{R}}}$

In which TD is the effective training session duration expressed in minutes and $\mathrm{HR}_{\mathrm{R}}{ }^{29}$ is determined with the expression $\left[\left(\mathrm{HR}_{\mathrm{TS}}-\mathrm{HR}_{\mathrm{B}}\right) /\left(\mathrm{HR}_{\max }-\mathrm{HR}_{\mathrm{B}}\right)\right]$, where $H_{T S}$ is the average training-session heart rate and $\mathrm{HR}_{\mathrm{B}}$ is the heart rate measured at rest. The HRbased method proposed by Edwards ${ }^{23}$ was also used as a common indicator of internal TL in various disciplines. The criterion-related validity between Banister's TRIMP and Edwards's TL was verified in many studies, such as that of Borresen and Lambert ${ }^{30}$, who found high significant correlation between these two HR-based methods ( $r=0.98 ; 95 \% \mathrm{Cl}: 0.96$ to 0.99 ). Recently, this method was published in a review article of Borresen and Lambert ${ }^{30}$ as an index of training stress like Banister's TRIMP and Lucia's TRIMP. Practically all the research analyzing the ecological validity of session-RPE has used this HR-based method, such as Impellizzeri et al., ${ }^{21}$ for instance.

This method determines internal load by measuring the product of the accumulated training duration (min- utes) in five HR zones by a coefficient relative to each zone $\left(>50-60 \%\right.$ of $\mathrm{HR}_{\max }=1,>60-70 \%$ of $\mathrm{HR}_{\max }=2,>70-80 \%$ of $\mathrm{HR}_{\max }=3,>80-90 \%$ of $\mathrm{HR}_{\text {max }}=4$, and $>90-100 \%$ of $\mathrm{HR}_{\max }=5$ ), and then summing the results.

\section{HR Measurements and Calculations}

Training intensity during each Karate training camp session ${ }^{13}$ was recorded using HR monitors (Polar Team System, Polar, Kempele, Finland), with HR recorded every 5-s. After each training session, HR data were downloaded to a computer using appropriate software (Polar Advantage Software, Polar Electro, Oy, Finland). To assess resting HR, athletes did lay on a bed for 10-min at 6:20 a.m. The resting HR value corresponded to the minimal HR observed during this $10-$ min period.

\section{Statistical Analysis}

Data were analyzed using SPSS 15.0 statistical software package (SPSS Inc., Chicago, IL). Descriptive statistics were expressed as mean $\pm S D$. Normality of the distribution for outcome measures was tested using the Kolmogorov-Smirnov test. The sample size was established with post-hoc statistical power analysis with G-Power 3.1.331. Pearson product-moment correlation coefficients were calculated to determine whether session-RPE and the various HRbased TL methods were convergent. The magnitude of the correlations was determined using the modified scale of Hopkins: $r \leq 0.1$, trivial; $>0.1-0.3$, small; $>0.3-0.5$, moderate; $>0.5-0.7$, large; $>0.7-0.9$, very large; $>0.9-<1$, nearly perfect; and 1 perfect. Significance and meaningful acceptance of the correlation were set at $5 \%(p<0.05)$ and 0.5 (large to perfect), respectively.

\section{Results}

The HR and RPE were collected from 10 training sessions with inter-day (two sessions for days) correlations were determined (Tab. 2) $(n-11 \times 5$ days). The pattern of session-RPE and Banister's TRIMP during the $1 \mathrm{wk}$ of the intensive training camp is shown in Figure 1. The mean session-RPE values and correlations in each exercise mode between session-RPE and HR-based TLs (i.e., Edwards's TL and Banister's TRIMP) showed TL, $r=0.79 ; 95 \% \mathrm{Cl}: 0.67$ to 0.87 and Banister's TRIMP, $r=0.63 ; 95 \% \mathrm{Cl}: 0.44$ to 0.77 .

\section{Discussion}

To our knowledge, the present study is the first to apply Foster's RPE-based approach ${ }^{11}$ to quantify internal TL during different modes of karate training in young karate practitioners and to demonstrate significant correlations between this method and other pub- 
Table 2. Inter-day correlations between session RPE and HR based training loads.

\begin{tabular}{|c|c|c|c|c|c|c|c|}
\hline \multirow[t]{2}{*}{ Day } & \multirow{2}{*}{$\begin{array}{l}\text { Number of } \\
\text { Sessions }\end{array}$} & \multicolumn{4}{|c|}{$\mathrm{Cl}(95 \%)$} & \multicolumn{2}{|c|}{$\mathrm{Cl}(95 \%)$} \\
\hline & & $\begin{array}{l}\text { Banister's } \\
\text { TRIMP }\end{array}$ & $\begin{array}{l}\text { Lower } \\
\text { Limit }\end{array}$ & $\begin{array}{l}\text { Upper } \\
\text { Limit }\end{array}$ & $\begin{array}{l}\text { Edwards's } \\
\text { TL }\end{array}$ & $\begin{array}{l}\text { Lower } \\
\text { Limit }\end{array}$ & $\begin{array}{l}\text { Upper } \\
\text { Limit }\end{array}$ \\
\hline$D 1$ & 2 & $0.97^{*}$ & 0.89 & 0.99 & $0.89^{*}$ & 0.64 & 0.97 \\
\hline$D 2$ & 2 & $0.88^{*}$ & 0.61 & 0.97 & $0.87^{\star}$ & 0.58 & 0.96 \\
\hline D3 & 2 & $0.92^{*}$ & 0.71 & 0.97 & $0.84^{*}$ & 0.50 & 0.95 \\
\hline$D 4$ & 2 & $0.91^{*}$ & 0.68 & 0.97 & $0.85^{\star}$ & 0.53 & 0.96 \\
\hline D5 & 2 & $0.91^{*}$ & 0.68 & 0.97 & $0.92^{*}$ & 0.73 & 0.98 \\
\hline
\end{tabular}

* Significant at $p<0.001$.

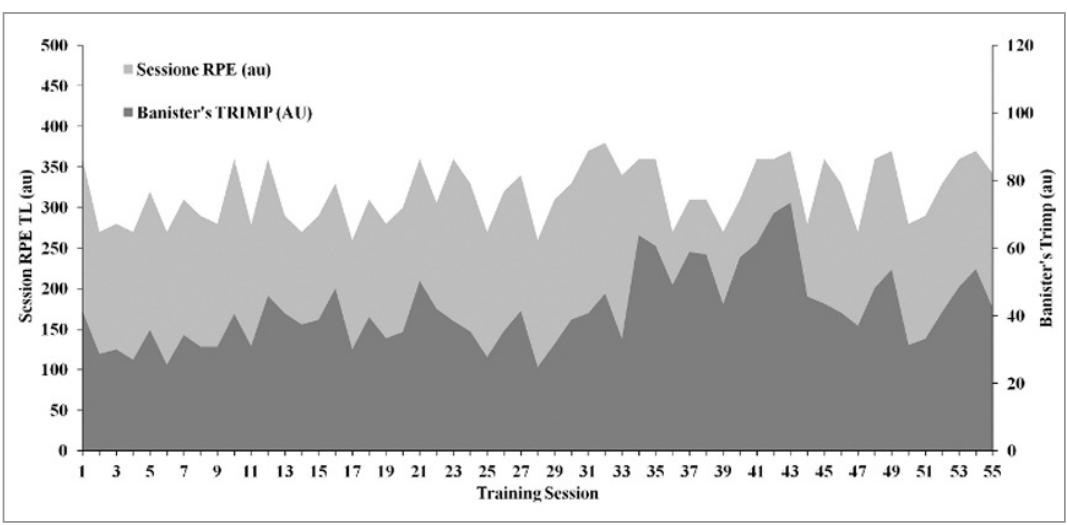

Figure 1. Profile of the session rate of perceived exertion training load (TL) vs Edwards's TL method across the training sessions examined during the training camp (55 training sessions).

lished methods based on the HR response to exercise. Specifically, we determined the correlations (validity) between session-RPE and two HR-based methods widely considered to be valid indicators of internal TL during all modes of training sessions present at the training camp. The correlations between session-RPE and Banister's TRIMP and Edwards's TL were, $r=0.63$ "moderate" and $r=0.79$ "large", respectively. The magnitudes of the correlations were similar to those reported in other investigations ${ }^{32}$. A possible explanation for the strongly correlations revealed in the present study could be the relatively high anaerobic contribution to energy production during karate training, which is characterized by intermittent exercises relying on both aerobic and anaerobic sources $^{8}$. The magnitude of the association between the session-RPE and HR-based TLs was high enough to confirm that session-RPE can be used as a valid alternative for quantifying training loads during special physical training in young karate practitioners. These results are consistent with the study of Foster et al., ${ }^{11}$ who showed that individual correlations between the session-RPE method and Edward's TL ranged between $r=0.75$ and 0.90 , but no statistical methods were explained in this study.

On the other hand, Perandini et al. ${ }^{33}$ in a study conducted with taekwondo athletes found a lower but significant correlation between session-RPE and Banister's TRIMP $(r=0.52, \mathrm{p}=0.02)$ and Edward's TL $(r=$ $0.64, p<0.01)$. Since HR may not be an appropriate global measure of exercise intensity in steady state and interval exercises, this lower correlation seems to be due to the high-intensity exercise nature investigated during the training session. In this context, RPE has been shown to offer a simple and valid method for quantifying whole-training-session intensity in high-intensity intermittent exercise ${ }^{9}$. In the present study, the correlation between session-RPE and Banister's TRIMP was $r=0.63(p<0.01)$ while Edwards's TL was $r=0.79$ ( $p<0.001)$, which confirms the validity of the RPE method as an accurate mode of training load monitoring during intermittent exercise. The study of Earnest et al. ${ }^{34}$ showed that the RPE method might provide a more accurate training load's monitoring compared to the other methods based on HR when both aerobic and anaerobic metabolisms are activated simultaneously. Study strength appears in group homogeneity, while sample size $(n=11)$ could be a limit of this study as first impression. However, it is important to note that simple size was satisfied by the statistical power.

The results of the present study provide evidence that the session-RPE method is a simple and inexpensive tool that accurately provides a similar quantification of internal TLs as assessed by the HR-based methods during the various training modes with young karate practitioners. The complex physiological interactions during karate sessions that were dedicated for developing a wide variety of physical capacities makes it difficult for coaches to accurately quantify training load using HR or time measures ${ }^{35,36}$. Thus, the session-RPE method provides a practical, low-cost, and non invasive tool of quantifying karate training loads, thus making it a valuable tool for athletes, coaches, 
and sports scientists. Considering that nonfunctional overreaching and overtraining induce fatigue, performance detriment, more severe symptomatology and maladapted physiology (psychologic, neurologic, endocrinologic, immunologic systems), RPE-session method could be a useful non invasive tool to prevent these symptoms ${ }^{8}$.

\section{Competing interests}

The authors declare no conflict of interest related to the present manuscript.

\section{Funding}

No funding was received for this article.

\section{Authors Contribution}

All authors contributed equally to this manuscript.

\section{References}

1. Chaabene H, Hachana Y, Franchini E, Mkaouer B, Chamari K. Physical and physiological profile of elite karate athletes. Sports Med. 2012;42(10):829-843.

2. Beneke R, Beyer T, Jachner C, Erasmus J, Hutler M. Energetics of karate kumite. Eur J Appl Physiol. 2004;92(4-5):518523.

3. Lide K, Imamura H, Yoshimura Y, et al. Physiological responses of simulated karate sparring matches in young men and boys. J Strength Cond Res. 2008; 22(3):839-844.

4. Chaabene H, Franchini E, Miarka B, Selmi MA, Mkaouer B, Chamari K. Time-Motion Analysis, Physiological and Rate of Perceived Exertion Responses to Karate Official Combats: Is There a Difference Between Winners and Defeated Karatekas? Int J Sports Physiol Perform. 2013. [Epub ahead of print]

5. Ravier G, Dugue B, Grappe F, Rouillon JD. Impressive anaerobic adaptations in elite karate athletes due to few intensive intermittent sessions added to regular karate training. Scand $J$ Med Sci Sports. 2009;19(5):687-694.

6. Vernillo G, Agnello L, Drake A, Padulo J, Piacentini MF, La Torre A. An observational study on the perceptive and physiological variables during a 10,000-m race walking competition. J Strength Cond Res. 2012;26(10):2741-2747.

7. Padulo J, Degortes N, Migliaccio GM, et al. Footstep manipulation during uphill running. Int J Sports Med. 2013;34(3):244247.

8. Foster C. Monitoring training in athletes with reference to overtraining syndrome. Med Sci Sports Exerc. 1998;30(7):11641168.

9. Haddad M, Chaouachi A, Castagna C, Wong dP, Behm DG, Chamari K. The construct validity of session RPE during an intensive camp in young male Taekwondo athletes. Int J Sports Physiol Perform. 2011;6(2):252-263.

10. Barroso R, Cardoso RK, do Carmo EC, Tricoli V. Perceived Exertion in Coaches and Young Swimmers With Different Training Experience. Int J Sports Physiol Perform. 2014;9 (2):212-216

11. Foster C, Florhaug JA, Franklin J, et al. A new approach to monitoring exercise training. J Strength Cond Res. 2001;15 (1):109-115

12. Padulo J, Mignogna P, Mignardi S, Tonni F, D'Ottavio S. Effect of Different Pushing Speeds on Bench Press. Int J Sports Med. 2012; 33(5):376-380.

13. Vando $S$, Filingeri $D$, Maurino $L$, Chaabene $H$, Bianco $A$, et al. Postural Adaptations in Preadolescent Karate Athletes Due to a one Week Karate Training Camp. J Hum Kinet. 2013:38(8):45-52.

14. Vando S, Unim B, Cassarino SA, Padulo J, Masala D. Effectiveness of perceptual training - proprioceptive feedback in a virtual visual diverse group of healthy subjects: a pilot study. Epidemiology Biostatistics and Pubblic Health. 2013;10(2): e8844-1-e8844-10.

15. Granatelli G, Gabbett TJ, Briotti G, et al. Match Analysis and Temporal Patterns of Fatigue in Rugby Sevens. J Strength Cond Res. 2013. [Epub ahead of print]

16. Imamura H, Yoshimura Y, Uchida K, Nishimura S, Nakazawa AT. Maximal oxygen uptake, body composition and strength of highly competitive and novice karate practitioners. Appl Human Sci. 1998;17(5):215-218.

17. Eston R. Use of ratings of perceived exertion in sports. Int $J$ Sports Physiol Perform 2012;7(2):175-182.

18. Padulo J, Powell D, Milia R, Ardigo LP. A paradigm of uphill running. PLoS One 2013;8(7):e69006.

19. Fabre N, Mourot L, Zerbini L, Pellegrini B, Bortolan L, Schena F. A novel approach for lactate threshold assessment based on rating of perceived exertion. Int J Sports Physiol Perform. 2013;8(3):263-270.

20. Scott TJ, Black CR, Quinn J, Coutts AJ. Validity and reliability of the session-RPE method for quantifying training in Australian football: a comparison of the CR10 and CR100 scales. J Strength Cond Res. 2013;27(1):270-276.

21. Impellizzeri FM, Rampinini E, Marcora SM. Physiological assessment of aerobic training in soccer. J Sports Sci. 2005;23 (6):583-592.

22. Banister EW. Modeling elite athletic performance. In: Green H, McDougal $\mathrm{J}$, Wenger $\mathrm{H}$, eds Modeling elite athletic performance Champaign: Human Kinetics. 1991;403-424.

23. Edwards S. High performance training and racing. In: Edwards $\mathrm{S}$, ed High performance training and racing Sacramento, CA Feet Fleet Press. 1993;113-123.

24. Milanez VF, Spiguel Lima MC, Gobatto CA, Perandini LA, Nakamura FY, Ribeiro LFP. Correlates of session-rate of perceived exertion (RPE) in a karate training session. Sci Sports. 2013;26(1):38-43.

25. Tabben M, Sioud R, Haddad M, et al. Physiological and perceived exertion responses during international karate kumite competition. Asian J Sports Med. 2013.

26. Padulo J, Oliva F, Frizziero A, Maffulli N. Muscles, Ligaments and Tendons Journal. Basic principles and recommendations in clinical and field science research. MLTJ. 2013;4 250-252.

27. Miller WC, Wallace JP, Eggert KE. Predicting max HR and the HR-VO2 relationship for exercise prescription in obesity. Med Sci Sports Exerc. 1993;25(9):1077-1081.

28. Haddad M, Dridi A, Moktar C, et al. Static Stretching Can Impair Explosive Performance For At Least 24 Hours. J Strength Cond Res. 2013. [Epub ahead of print]

29. Padulo J, Di Capua R, Viggiano D. Pedaling time variability is increased in dropped riding position. Eur J Appl Physiol. 2012 112(8):3161-3165.

30. Borresen J, Lambert MI. The quantification of training load, the training response and the effect on performance. Sports Med. 2009; 39(9):779-795

31. Faul F, Erdfelder E, Lang AG, Buchner A. G*Power 3: a flexible statistical power analysis program for the social, behavioral, and biomedical sciences. Behav Res Methods. 2007;39 (2):175-191 


\section{J. Padulo et al.}

32. Borresen J, Lambert MI. Quantifying training load: a comparison of subjective and objective methods. Int J Sports Physiol Perform. 2008;3(1):16-30.

33. Perandini LA, Siqueira-Pereira TA, Okuno NM, SoaresCaldeira LF, Nakamura FY. Use of session RPE to training load quantification and training intensity distribution in taekwondo athletes. Sci Sports. 2012;27(4):25-30.

34. Earnest CP, Jurca R, Church TS, Chicharro JL, Hoyos J, Lucia
A. Relation between physical exertion and heart rate variability characteristics in professional cyclists during the Tour of Spain. Br J Sports Med. 2004;38(5):568-575.

35. Padulo J, Tiloca A, Powell D, Granatelli G, Bianco A, Paoli A. EMG amplitude of the biceps femoris during jumping compared to landing movements. Springerplus. 2013;2:520.

36. Padulo J, Granatelli G, Ruscello B, D'Ottavio S. The place kick in rugby. J Sports Med Phys Fitness. 2013; 53(3):224-231. 